\title{
SISTEMA DE CONTROLE DA PRESSÃO DE COMBUSTÍVEL NO DIESEL COMMON RAIL
}

\author{
Mozart Fraga Martins ${ }^{1}$, Armando Antônio Maria Laganá ${ }^{1}$ e José Miguel Suen ${ }^{1}$ \\ ${ }^{1}$ Escola Politécnica da Universidade de São Paulo \\ E-mails: mozartfmartins@gmail.com, lagana@1si.usp.br, jmiguelsuen@gmail.com
}

\begin{abstract}
RESUMO
A injeção de combustível nos motores de ciclo diesel recebeu importantes aprimoramentos nas últimas décadas, entre as quais destacamos a adoção do sistema common rail. Trabalhando com alta pressão de combustível, aliada a um refinado controle dos injetores, os motores common rail, são capazes de proporcionar maior torque, eficiência energética, e redução nos índices de emissão de poluentes. Para a boa operação do sistema, é preciso uma pressão de combustível alta e bem controlada, em diferentes regimes de trabalho. Neste artigo, é descrita a modelagem e controle da válvula reguladora de pressão do rail. Foi levantado o modelo matemático do sistema, por meio de identificação não paramétrica. Seguido do projeto e aplicação de um controlador PID digital. Para identificação do modelo foi implementada uma plataforma constituída de bomba de alta, bomba de baixa, rail, sensor de pressão, válvula reguladora de pressão, injetores, motor elétrico e inversor de frequência. Os componentes utilizados são os mesmos do motor diesel 2.8L aplicado no veículo GM modelo S10. O presente controle será posteriormente utilizado para o desenvolvimento de uma ECU para o próprio motor citado.
\end{abstract}

\section{INTRODUÇÃO}

Os motores de combustão interna têm passado por um processo de contínua melhoria ao longo das últimas décadas, com o objetivo de atingir uma melhor eficiência energética e atender índices cada vez mais exigentes no controle da emissão de poluentes. Diversas tecnologias foram aplicadas com o intuito de otimizar estes geradores. Desde a adoção do controle eletrônico da injeção do combustível, à aplicação de novos materiais na construção dos motores, bem como a redução dos tamanhos destes, entre muitos outros aperfeiçoamentos adotados.

A melhoria construtiva nos motores se fez muito visível nos de ignição por compressão (CI) comumente chamado de ciclo Diesel, estes passaram ter maior rendimento com significativa redução de tamanho. Marcados por alterações na alimentação de combustível, na aplicação da sobre alimentação na admissão de ar, na adoção de sistemas de pós tratamento dos gases e particulados resultantes da queima do óleo diesel. [1]

As alterações na alimentação de combustível passaram pela aplicação das bombas rotativas, permitindo maior pressão de injeção, pela adoção das bombas mecânicas com gerenciamento eletrônico, pelos sistemas de unidades injetoras e o sistema common rail. Neste último a pressão 
de combustível passou a ser controlada de forma independente da rotação do motor de forma a garantir a pressão ideal para todas as faixas de trabalho.

O estudo do controle da pressão de combustível no diesel common rail norteia o trabalho descrito neste artigo. Sendo que no primeiro capítulo, será feito um breve histórico da evolução dos sistemas de alimentação de combustível; no segundo capítulo será introduzido o sistema common rail, bem como suas principais partes em relação a alimentação de combustível; no terceiro capitulo será discutida a técnica utilizada pela levantar o modelo matemático do sistema, juntamente com o cálculo do controlador a ser aplica e os resultados de sua aplicação e por fim na conclusão são levantadas as observações sobre a operação do sistema.

\section{INNJEÇÃO DE COMBUSTIVEL NOS MOTORES DIESEL}

Em 1982, Rudolf Diesel patenteia um novo tipo de motor de combustão interna. Seu projeto, era de um motor quatro tempos, diferenciando-se dos motores do ciclo Otto, pelo início da combustão ser através da injeção de combustível líquido na câmara, que ao entrar em contato com o ar aquecido pela compressão do cilindro dá inicio a combustão. O modelo apresentado era muito mais eficiente que os demais motores. Porém, Diesel unindo esforços e recursos com a companhia M.A.N. demorou 5 anos para a produção do seu motor, dados os desafios técnicos do projeto concebido por ele. [2]

Um dos grandes desafios para o motor Diesel são suas elevadas pressões de injeção de combustível. Ela inicia-se antes do ponto morto superior (PMS) e continua durante a descida do pistão. De forma que a pressão de injeção deve ser maior que a pressão existente dentro do cilindro. Atualmente os motores trabalham com pressões de injeção de aproximadamente 2000 bar. [3]

Sendo que os sistemas de injeção devem atender a três condições de operação. Primeiramente a pulverização do combustível, pois quanto menores forem as gotas de combustível mais facilmente ocorre a combustão, e esta atomização é dependente da pressão de injeção e do tamanho dos orifícios por onde passa o combustível. Em segundo a penetração do combustível, devendo haver tamanhos de gostas diferentes para garantir a dispersão do mesmo por toda a câmara, pois gotas menores irão vaporizar próximo ao bico e as maiores atingem os limites da câmara. Em terceiro controle da quantidade de injeção. [3]

Desta forma, a garantia da injeção de combustível sob alta pressão no interior do cilindro é princípio fundamental para a operação dos motores deste ciclo. E três maneiras são usadas para garantir esta injeção. O uso de bombas de injeção em linha ou rotativa, a utilização das unidades injetoras, e o sistema common rail.

Numa bomba de injeção, um modelo em linha por exemplo, um conjunto de êmbolos acionados por um eixo-excêntrico, por sua vez acoplado a arvore de manivelas do motor, serão os responsáveis pela injeção do combustível. No início do curso do êmbolo, a entrada de combustível é fechada e a quantia presa acima do pistão é forçado através de uma válvula de retenção para a linha de injeção. No fim da linha de injeção está o bico injetor. Que possui um ou mais orifícios através dos quais o combustível entra no cilindro. Nele, uma válvula com a carga de uma mola fecha esses orifícios, até que a pressão na linha de injeção atuando sobre a 
válvula, supere a força da mola e abra-a, permitindo a injeção. Esta elevação da pressão de combustível esta alinhada com a revolução da árvore de manivelas, e com o PMS de cada cilindro. A figura 1 exibe um modelo destas bombas. No caso das bombas rotativas, elas terão apenas um êmbolo e o combustível é distribuído entre os injetores. [2]

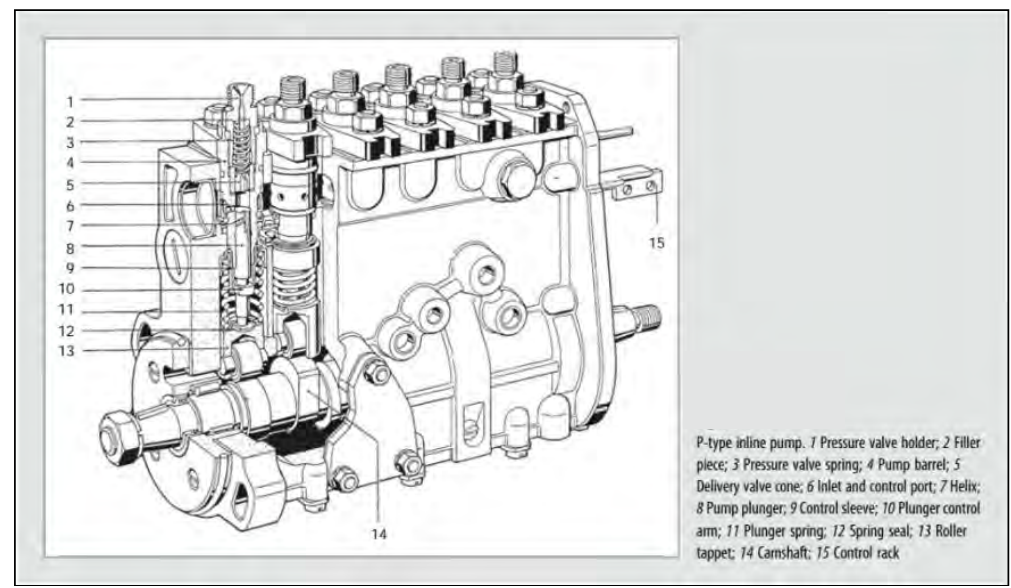

Figura 1 - Bomba injetora em linha [4]

Estas bombas podem servir a motores diesel que operem com injeção direta do combustível, ou arquiteturas que se utilizem de pré-câmaras, ou câmaras de turbilhonamento. Sendo que no segundo caso, as pressões de injeção são significativamente menores.

O sistema de injeção por unidades injetoras, ou bombas injetoras individuais, caracteriza-se por possuir uma por unidade de geradora de pressão cilindro do motor; impulsionadas pelo eixo de comando. O combustível nesse sistema atinge maiores pressões de injeção, podendo atingir pressões de aproximadamente 2000 bar, sendo injetado diretamente no cilindro. Válvulas solenoides para dosagem do combustível são integradas na unidade da bomba unitária. Sendo que a pressão de injeção ainda está atrelada ao movimento de subida do pistão sincronizado com os excêntricos da bomba injetora. A imagem abaixo descreve uma unidade injetora [4]

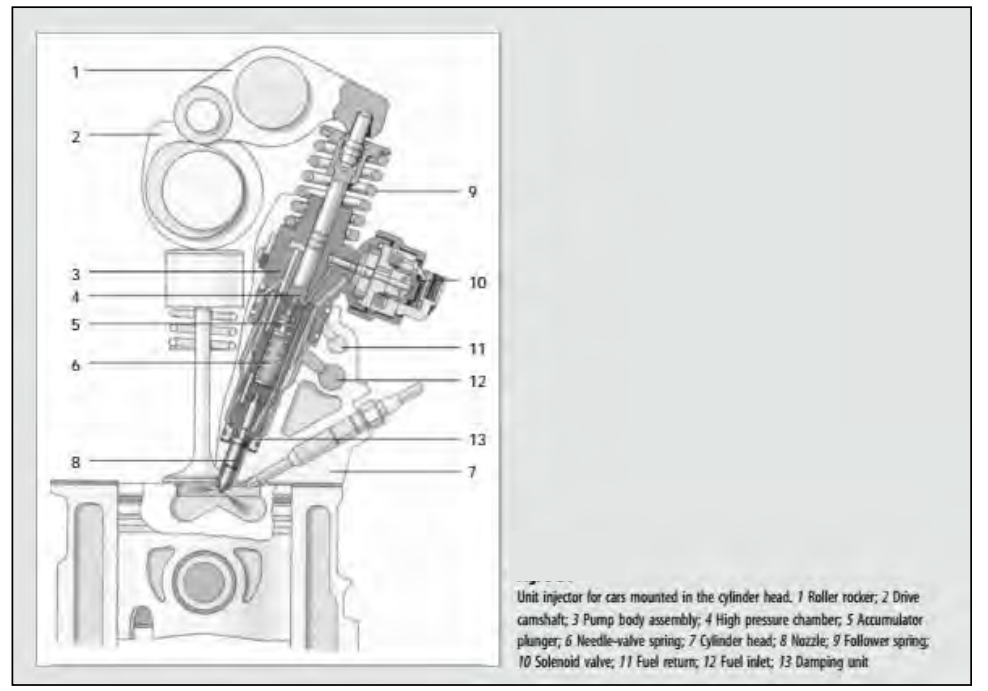

Figura 2 - Unidade Injetora [4]

Diferentemente dos sistemas de injeção acionados por excêntrico, no sistema common rail a geração de pressão ocorre de forma independente da fase de injeção. Uma bomba de alta pressão 
fornece o combustível pressurizado para o acumulador - tubo rail. Tubos de alta pressão conectam o rail com os injetores. Estes são como eletroválvulas, que injetam o combustível diretamente na câmara de combustão no tempo e na quantidade desejada. Isto ocorre de forma a desvinculada a rotação e carga do motor. Com as vantagens de manter uma pressão de injeção constante, permitir a flexibilidade no tempo de início da injeção, e na quantidade de combustível injetada e possibilitar a ocorrência de múltiplas injeções [4] A imagem 3 representa esquematicamente o sistema.

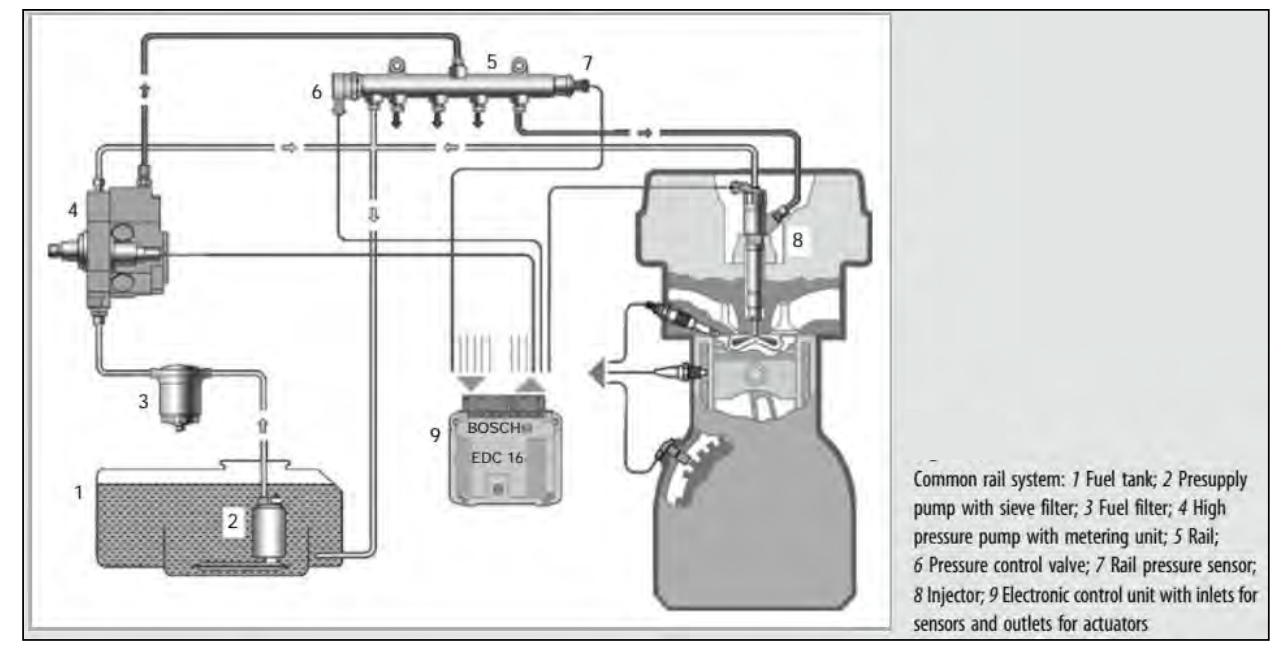

Figura 3 - Sistema common rail. [4]

\section{SISTEMA COMMON RAIL}

Segundo Konrad Reif [5] as exigências para os sistemas de injeção dos motores diesel são continuamente incrementadas. Atendendo a tais exigências os motores passaram a trabalhar com pressões elevadíssimas, rápidos tempos de injeção, e curvas de carga variadas. Tornando este motor mais econômico, limpo e potente. Avanço alcançado pelo sistema common rail. Ressaltando que a principal vantagem do common rail, é possibilitar a variação da pressão e tempo de injeção de forma ampla. O que foi possibilitado pela separação da geração de pressão, na bomba de alta, do sistema de injeção.

O sistema common rail pode ser dividido nos seguintes subsistemas [4]; sistema de baixa pressão e os componentes para suprimento de combustível (tanque, filtros, bomba de baixa pressão); sistema de alta pressão e seus componentes (bomba de alta pressão, rail, injetores, sensor de pressão do rail, válvulas de controle de pressão e dutos de alta pressão); e sistema de controle eletrônico (ECU, seus sensores e atuadores). Destes subsistemas, o de alta pressão e seu controle é foco deste trabalho.

\subsection{Sistema de alta pressão}

O sistema de alta pressão é responsável por promover a elevação da pressão de combustível, e entregar o débito necessário aos cilindros por meio dos injetores. Ele pode ser subdividido em geração de pressão, acumulação da pressão e entrega do combustível. 
Fazem parte deste sistema a bomba de alta pressão, o tubo acumulador (rail), sensor de pressão do rail, as válvulas de controle de pressão, tubos de alta pressão e os injetores. A bomba de alta pressão é acionada pelo motor, e promove a elevação da pressão de combustível, transferindo-o da linha de baixa para a de alta pressão. $O$ combustível é acumulado no rail, de onde irá ser succionado pelos injetores. A pressão é monitorada pelo sensor de pressão, permitindo a atuação do controle de pressão pela unidade de gerenciamento, que comanda a válvula dosadora e/ou a válvula controladora de pressão. Podendo haver três modelos de controle como mostra a figura 4.

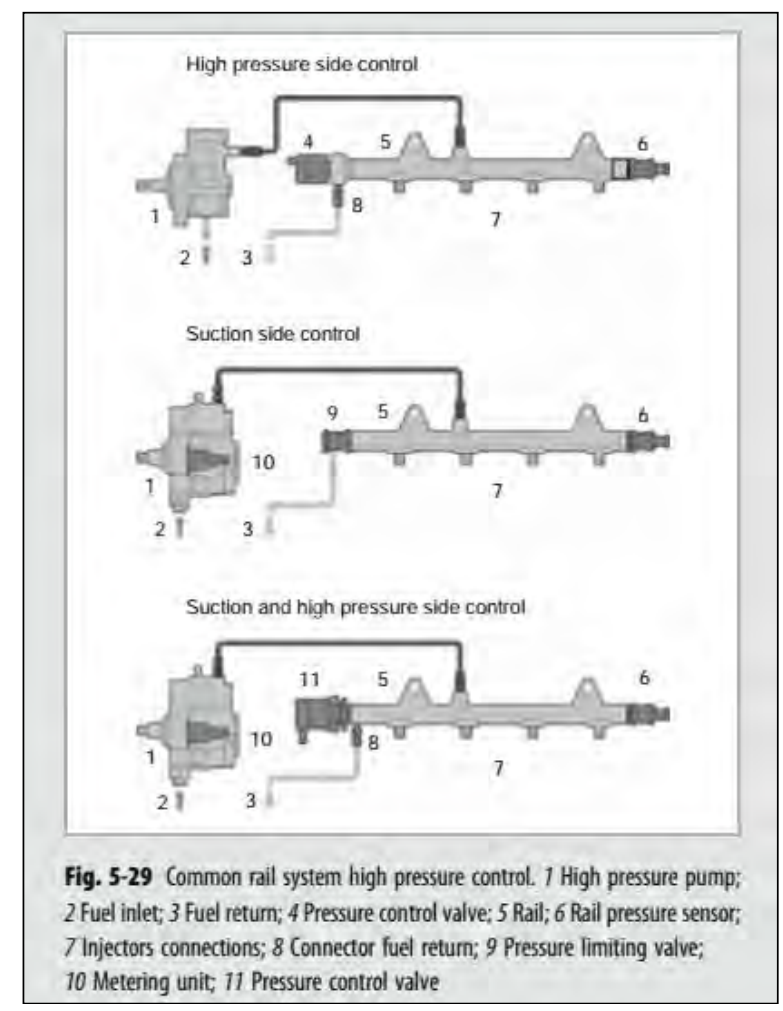

Figura 4 - Forma de controle da pressão de combustível [4]

No primeiro modelo o controle é feito na região de alta pressão por uma válvula solenoide, controlada pela unidade de gerenciamento. A bomba de alta, entrega a pressão máxima para o rail, é o excesso de combustível é descartado para a área de baixa pressão pela válvula reguladora. A desvantagem desse sistema, além do gasto desnecessário de energia para produzir alta pressão todo tempo, é a limitação desta a valor não muito elevador, na ordem de 1400 bar, visto que sistemas mais modernos ultrapassam os 2000 bar. [4]

No segundo modelo o controle é feito na entrega de combustível ao rail, uma válvula dosadora incorporada a bomba de alta pressão controla o fluxo de combustível que será pressurizado e enviado ao acumulador, enviando apenas o combustível necessário para manter a pressão do sistema. A vantagem deste método, é tornar menor o consumo de energia da bomba. Uma desvantagem seria a lentidão para que a pressão decaia no acumulador, em caso de regimes de carga negativos [4]. Esta arquitetura de controle de pressão equipa o sistema estudado neste artigo. 
No terceiro modelo, o controle é realizado tanto no lado de baixa, como de alta pressão. Unindo as características dos métodos anteriores. A válvula dosadora anexada a bomba de alta pressão regula a quantidade de combustível enviada para a câmara de pressurização, garantido o envio de combustível na quantidade requisitada pelo sistema. A válvula reguladora acoplada ao rail, garante a manutenção da pressão desejada, permitindo rápidos transientes [4].

\subsection{Caso de estudo}

O sistema estudado por este artigo é composto por uma bomba de baixa pressão e uma de alta, modelo Bosch $\mathrm{CP} 3$, contendo uma válvula dosadora acoplada a ela, que corresponde ao segundo método de controle descrito acima. Também compõe o sistema, o acumulador (rail), os tubos de alta pressão e os injetores. Este conjunto está montado em bancada como mostra a imagem 5 , sendo o sistema movido por um motor elétrico trifásico de $5 \mathrm{hp}$ controlado por um inversor de frequência.

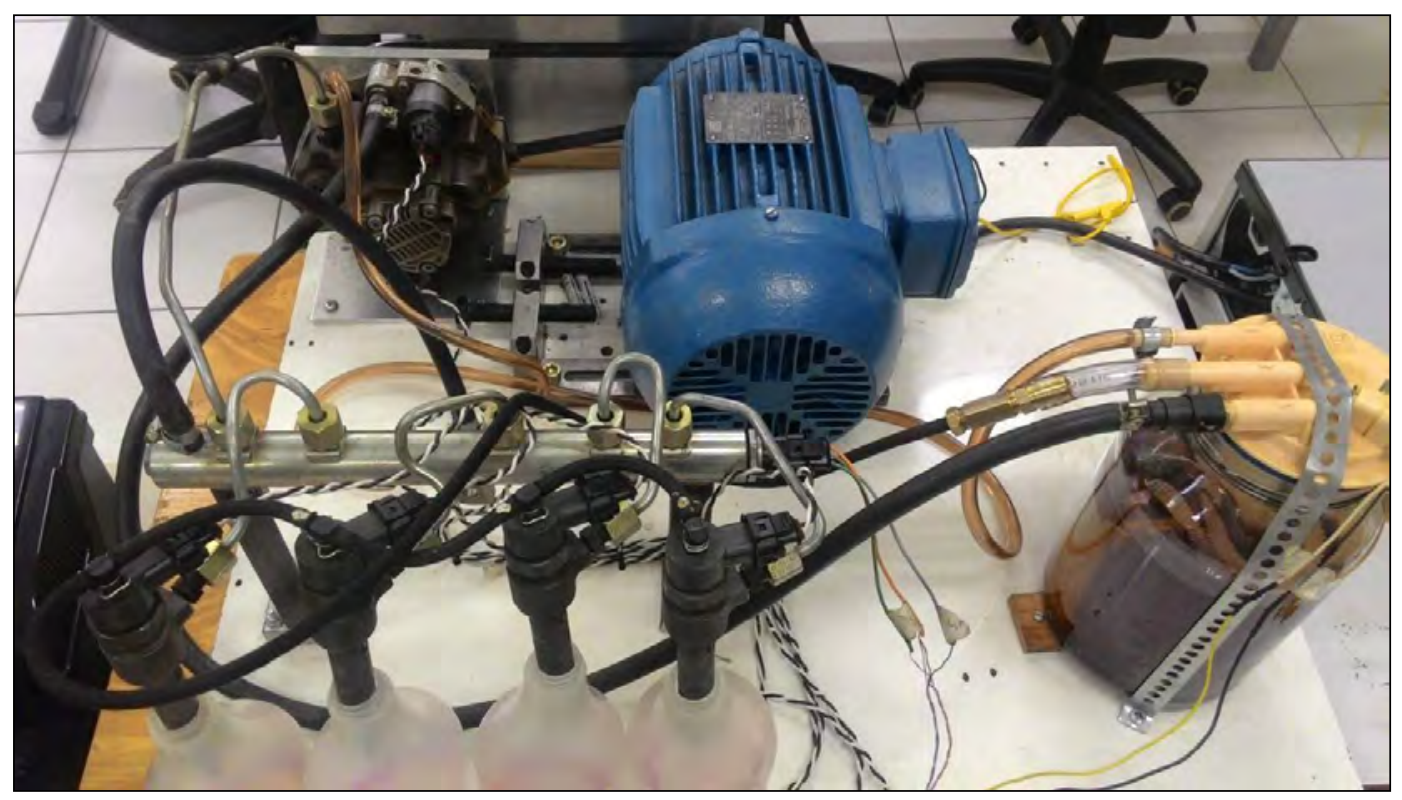

Figura 5 - kit de testes da pressão de combustível

\subsubsection{Bomba de alta pressão modelo Bosch CP3}

Esta bomba é composta de três êmbolos espaçados entre si num ângulo de $120^{\circ}$ de forma a permitir uma entrega uniforme de combustível.

O modelo de bomba CP3 da Bosch, é uma bomba de alta pressão radial de três pistões, estes três êmbolos estão espaçados entre si num ângulo de $120^{\circ}$. Ela possui controle da sucção, por meio da válvula dosadora, e uma bomba de engrenagens externa a ela, montada diretamente no corpo da bomba, auxilia no fornecimento de combustível. [4]

\subsubsection{Válvula dosadora}


Esta válvula solenoide presente na bomba de alta pressão controla a quantidade de combustível que é pressurizado. Ela é acionada pela unidade de gerenciamento com a aplicação de um sinal PWM. Quando desenergizada ela permite a passagem do combustível para o acumulador, que vai sendo restringido conforme a mesma é energizada. Assim, esta válvula é o atuador do sistema aqui analisado e sobre ela é feita a aplicação do sinal de controle. A figura 6 mostra a bomba CP3 e seus componentes.

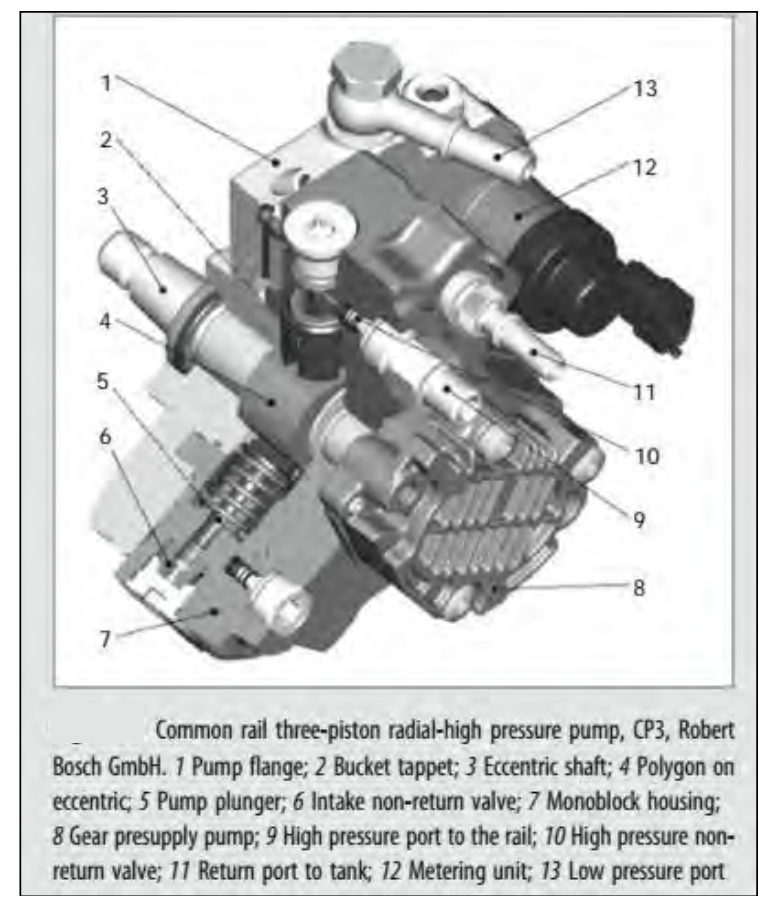

Figura 6 - Bomba de alta pressão CP3 [4]

\section{IDENTIFICAÇÃO CAIXA PRETA DO SISTEMA COMMON RAIL}

O sistema de alta pressão common rail corresponde a um complexo mecanismo, no qual muitos fatores podem afetar a injeção de combustível, tais como vazamento de combustível entre vários de seus componentes, a deformação elástica dos tubos de combustível de alta pressão, compressibilidade de combustível sob alta temperatura e alta pressão, entre outros, de forma [6]. Todos estes fatores devem ser levados em consideração na composição de um modelo matemático preciso do sistema. Sendo a modelagem do sistema feita parcialmente em cada sistema, e depois associados de forma a gerar um modelo global que permita o controle do mesmo [7]. Porém tal tarefa se torna extremamente onerosa para aplicações de curto prazo.

Como forma de permitir ensaios mais rápidos, propõe-se aqui a utilização da identificação do modelo do sistema pelo método empírico, criando um modelo em "caixa preta", definido a partir de dados experimentais, com o monitoramento das entradas e saídas do sistema.

Para o levantamento do modelo optou-se por aplicar um degrau de tensão na válvula dosadora. Como supracitado esta válvula é acionada por um PWM comandado pela central. Repetimos na bancada a mesma estratégia de acionamento da válvula presente na ECU do veículo, estando um lado da válvula diretamente ligada a tensão de bateria, e outro em um driver de potência chaveando a ligação ao aterramento. O PWM inicial aplicado ao sistema foi comandado com 
um duty cicle de $99 \%$, sendo então aplicado um degrau ao valor do duty cicle, então alterado para $92 \%$. A resposta a aplicação destes diferentes duty cicle's foi monitorada por meio da resposta do sensor de pressão do Rail. Este sensor apresenta uma resposta linear à pressão no interior do acumulador de combustível.

Tal variação foi lida por uma entrada A/D do microcontrolador. Esta tensão lida, foi então convertida pelo algoritmo embarcado num valor de pressão equivalente do sistema. Para realizar a conversão, previamente foi realizada uma medição empírica no veículo para levantar a curva de variação de pressão versus tensão do sensor. Optou-se por utilizar o PIC18F4550 para realizar o controle do PWM da válvula e o monitoramento da tensão do sensor. A figura a seguir mostra a placa de controle e aquisição montada para o projeto.

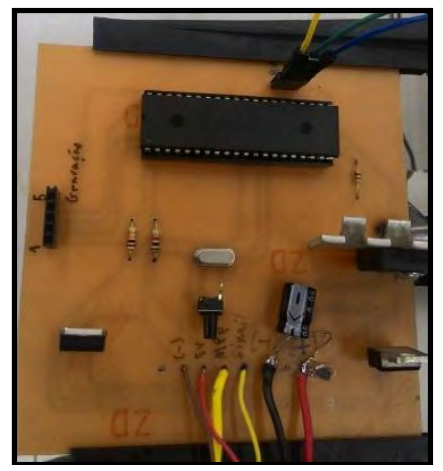

Figura 7 - Placa de controle [Autor]

Os dados obtidos foram enviados por comunicação serial para o computador, e salvos neste no formato ".csv" para que pudessem ser devidamente manipulados. E foram coletados com uma taxa de 40 amostras por segundo. Assim, com a população de dados em mãos, optou-se por fazer sua análise utilizando o software MATLAB ${ }^{\circledR}$.

Como primeiro parâmetro a ser analisado busca-se observar a resposta do sistema a entrada em degrau. Visto que através da análise desta pode-se compreender o comportamento dinâmico do sistema [6]. A figura a seguir representa o comportamento do sistema em função da entrada em degrau.

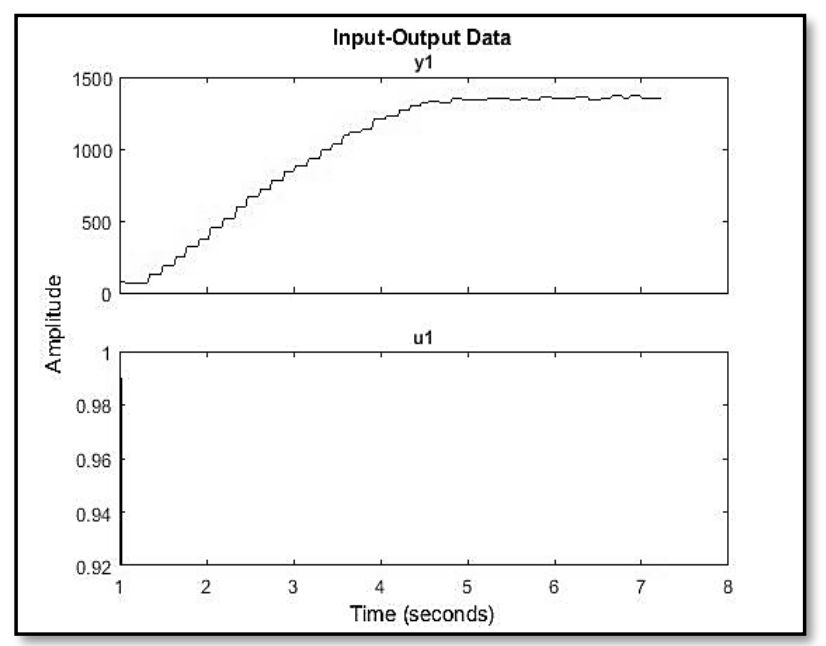

Figura 8 - Resposta do sistema à entrada em degrau [Autor] 
A estimação da função de transferência foi realizada com o auxílio da toolbox de identificação presente no MATLAB. O sistema em questão passa a ser descrito pela função de transferência descrita na equação 1 .

$$
G(s)=\frac{794}{s+0,477}
$$

A função de transferência descrita acima, aproxima o sistema estudado a um modelo de primeira ordem. Pela comparação do comportamento do sistema com a função gerada pode-se comparar a compatibilidade do modelo com a planta analisada. Comparação feita via software MATLAB® e mostrada na figura 9.

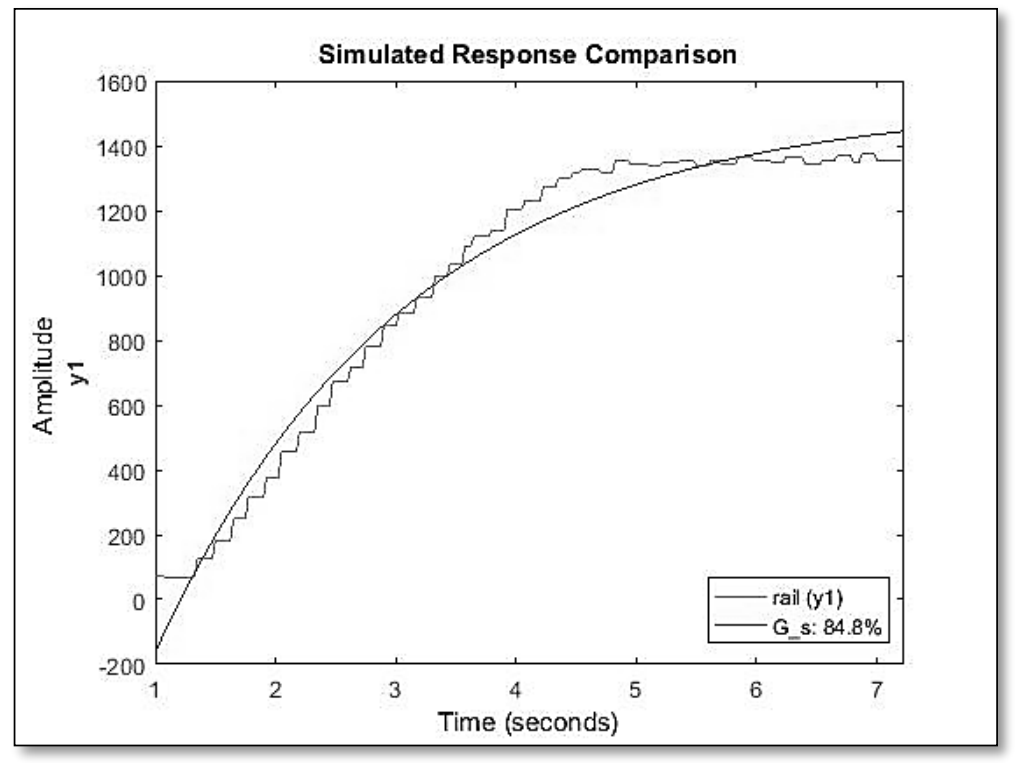

Figura 9 - Comparação do modelo obtido com a resposta da planta

Como pode-se observar o percentual de compatibilidade do modelo é de $84,8 \%$, o que indica uma boa aproximação do modelo estimado com o comportamento da planta.

\section{PROJETO E IMPLEMENTAÇÃO DO CONTROLADOR}

O próximo passo foi o projeto do controlador implementado, observando alguns requisitos de desempenho desejados para o para o sistema:

- $M p=20 \%$

- Tempo de subida de 2 segundos

Com base nos requisitos acima, foi projetado um controlador PID digital para o sistema. $\mathrm{O}$ projeto foi feito utilizando o MATLAB® para a realização dos cálculos, conforme o algoritmo a seguir.

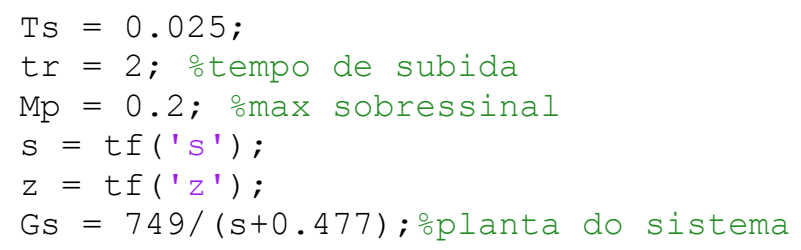


zeta $=\operatorname{sqrt}\left(\left((\log (\mathrm{Mp}) / \mathrm{pi})^{\wedge} 2\right) /\left(\left((\log (\mathrm{Mp}) / \mathrm{pi})^{\wedge} 2\right)+1\right)\right) ;$ ocoeficiente de amortecimento

teta $=\operatorname{acos}($ zeta $)$;

wd $=($ pi-teta $) /$ tr; $\%$ frequencia amortecida

$\mathrm{wn}=\mathrm{wd} /\left(\operatorname{sqrt}\left(1-\right.\right.$ zeta^$\left.\left.^{\wedge}\right)\right) ;$ ofrequencia natural

s0 $=-$ zeta $^{*} w n+j{ }^{*} w d ;$

$\mathrm{z} 0=\exp (\mathrm{s} 0 * \mathrm{Ts})$;

$\mathrm{Gz}=\mathrm{c} 2 \mathrm{~d}\left(\mathrm{Gs}, \mathrm{Ts}, \mathrm{z}^{\prime} \mathrm{oh}\right.$ ');

$c 2=0$;

phi=-pi-angle (evalfr $\left.\left(G z^{*}\left((z-c 2) /\left(z^{*}(z-1)\right)\right), z 0\right)\right)$;

$\mathrm{cl}=-(\operatorname{imag}(\mathrm{z} 0) / \tan (\mathrm{phi}))+\operatorname{real}(\mathrm{z} 0) ; \circ \mathrm{condição} \mathrm{de} \mathrm{fase}$

$\mathrm{K}=1 / \operatorname{abs}\left(\operatorname{evalfr}\left(G z^{*}((z-c 1) *(z-c 2) /(z *(z-1))), z 0\right)\right)$; 。 condição de modulo

$\mathrm{Cz}=\mathrm{K}^{\star}(\mathrm{z}-\mathrm{C} 2) *(\mathrm{z}-\mathrm{C} 1) /\left(\mathrm{z}^{\star}(\mathrm{z}-1)\right) ; \mathrm{zpk}(\mathrm{Cz})$

num $=\mathrm{Cz} \cdot \operatorname{num}\{:\} ;$ den $=\mathrm{Cz} \cdot \operatorname{den}\{:\}$;

$\mathrm{kp}=(\mathrm{K} / 2) *\left(\mathrm{c} 1+\mathrm{c} 2-3{ }^{*} \mathrm{c} 1{ }^{*} \mathrm{c} 2+1\right)$

$t i=(T s / 2) *\left(\left(c 1+c 2-3{ }^{*}{ }^{*}{ }^{*} \mathrm{C} 2+1\right) /\left(1+\mathrm{c} 1{ }^{*} \mathrm{C} 2-\mathrm{c} 1-\mathrm{c} 2\right)\right)$

$\mathrm{td}=2 * \mathrm{Ts} \star\left(\left(\mathrm{c} 1{ }^{*} \mathrm{c} 2\right) /(\mathrm{c} 1+\mathrm{c} 2-3 * \mathrm{c} 1 * \mathrm{c} 2+1)\right)$

$\mathrm{N}=3$; $\frac{\circ}{p}$ arametro entre 3 e 20 - Acrescenta um novo polo em (-N*Td)

param $=[\mathrm{kp}$ ti td $\mathrm{Ts} \mathrm{N}]$

O controlador calculado é mostrado na equação (2).

$$
C(z)=0,00079517 \frac{\mathrm{z}(\mathrm{z}-0,945)}{\mathrm{z}(\mathrm{z}-1)}
$$

A figura 10 , mostra a resposta da planta com o controlador calculado.

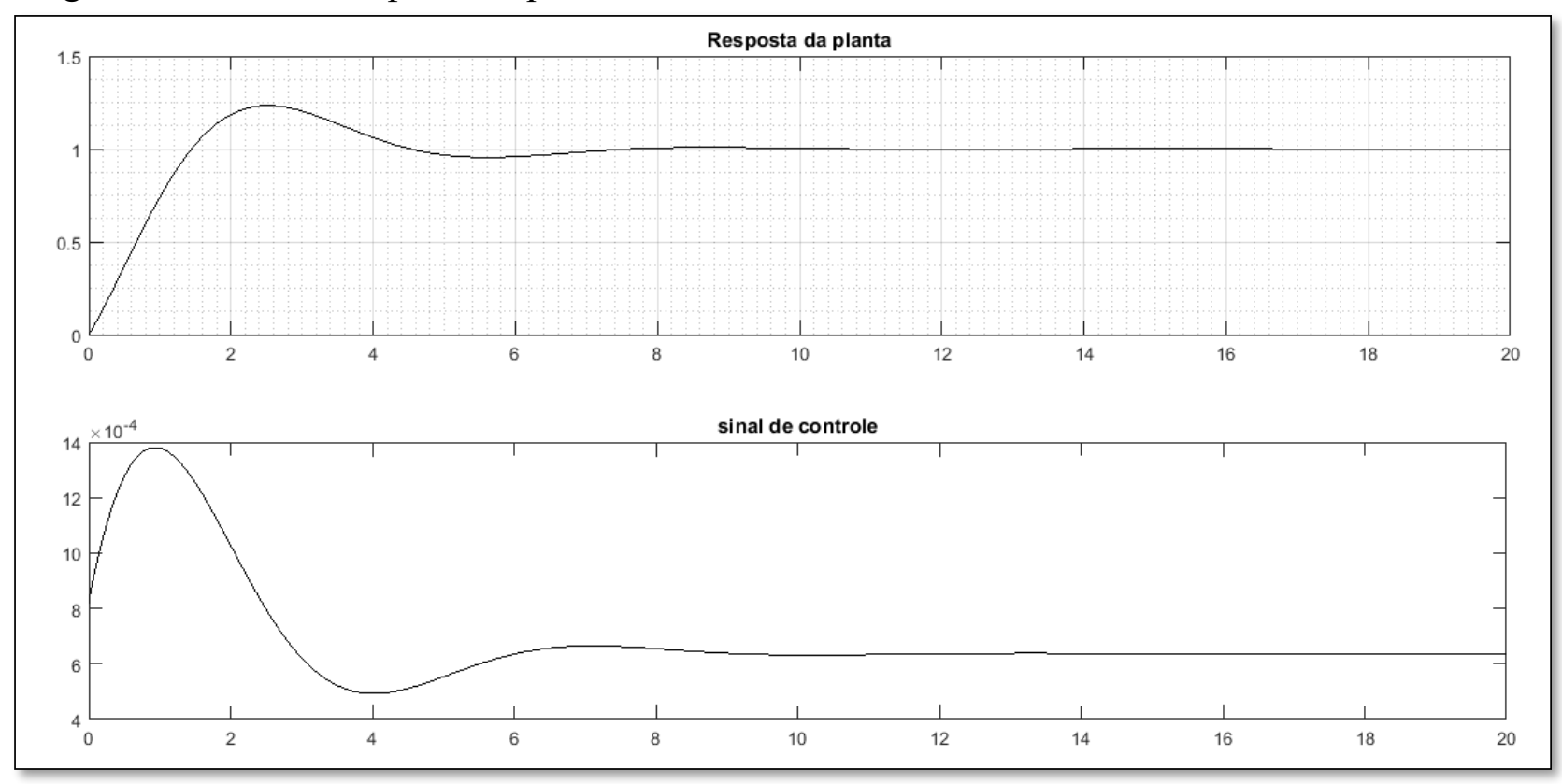

Figura 10 - Resposta da planta com o controlador 


\subsection{Implementação no hardware}

Para a aplicação prática do controlador, ele foi inserido no algoritmo de um hardware microcontrolado. O diagrama abaixo exemplifica esta aplicação. A partir do valor de setpoint informado pelo usuário, valendo ressaltar que este valor poderia ser um dado tabelado e implementado por uma máquina de estados, o algoritmo calcula o erro e define o novo valor de PWM para se alcançar o valor desejado. A verificação da pressão desejada é feita pela variação de tensão sensor de pressão do rail. Esta tensão lida por um $\mathrm{A} / \mathrm{D}$ do microcontrolador é usada para calcular o monitorar a saída. $\mathrm{O}$ sistema foi inicializado com um setpoint de 80 bar.

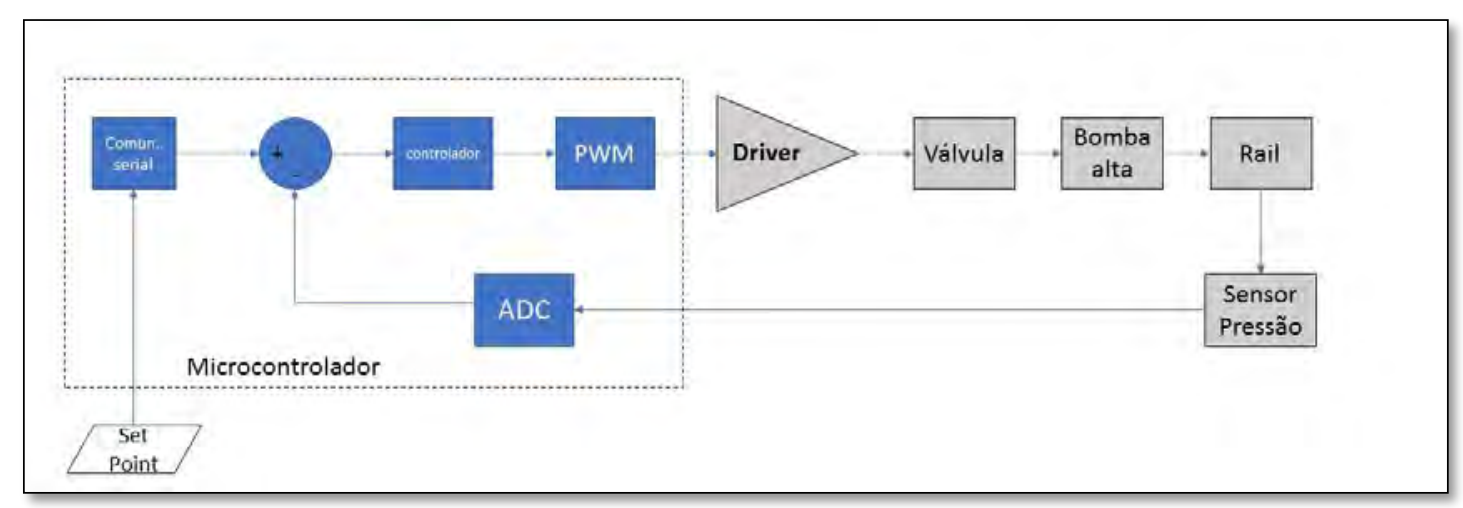

Figura 11 - Diagrama de blocos do controle

A equação de diferenças foi implementada em código "C" e aplicada no microcontrolador, pelo script abaixo.

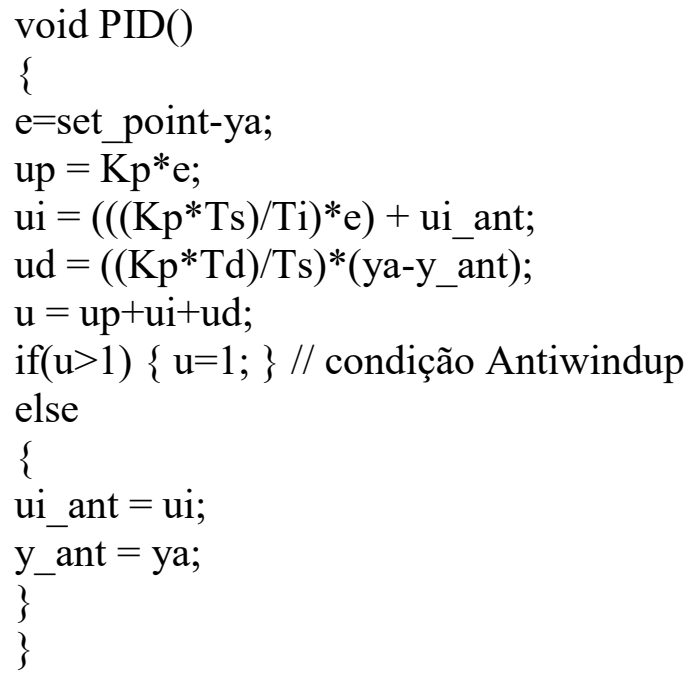

Onde "e" é o erro de posição da enésima amostra, "u" é a ação de controle da enésima amostra, "up, ui e ud" são respectivamente as parcelas proporcional, integral e derivativa da enésima iteração, "ui_ant" a parcela integrativa da iteração anterior. Sendo "ya" é a saída da enésima amostra e "ya_ant" a saída da amostra anterior.

A figura a seguir mostra a resposta do sistema para um setpoint de 350 bar, que é um valor comumente monitorado nos veículos para rotação em marcha lenta. Lembrando 
que o sistema inicia estabilizando numa pressão de 80 bar, e depois persegue o setpoint informado.

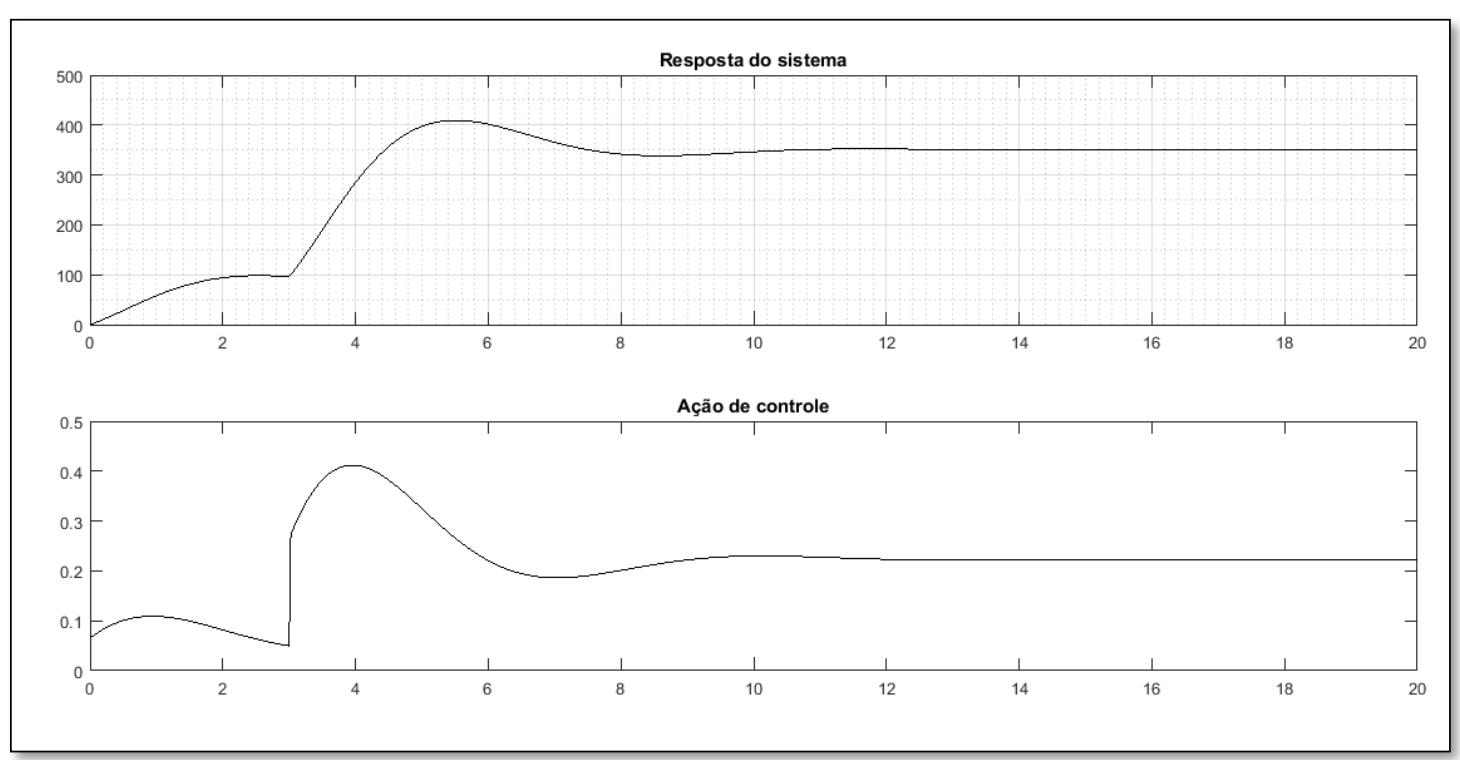

Figura 12 - Resposta do sistema para um setpoint de 350 bar

Na figura 13, é mostrada a resposta do sistema partindo de uma pressão de 350 bar para um setpoint de 1200 bar, a partir de um intervalo de 10 segundos.

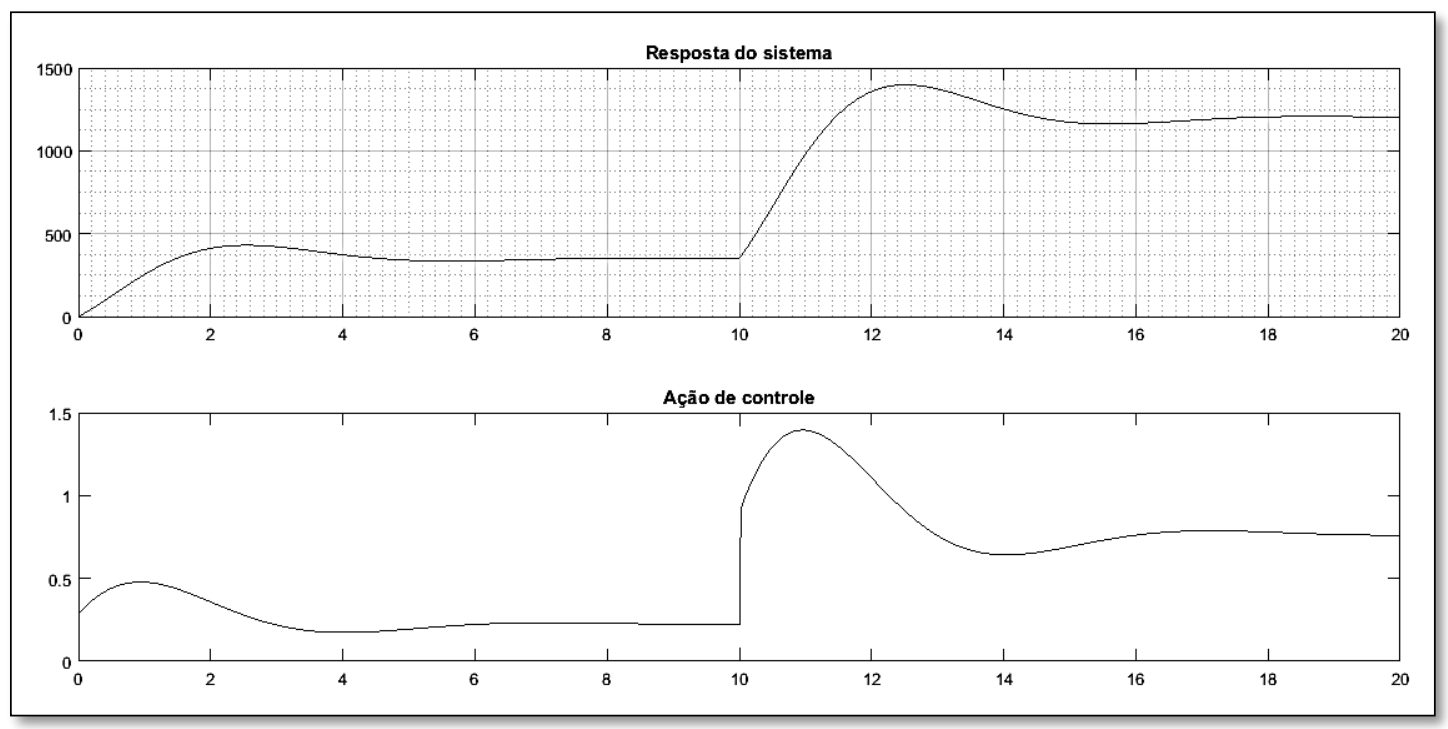

Figura 13 - Resposta para um setpoint de 1200 bar

Pode-se observar que os requisitos iniciais delimitados para o sistema foram alcançados. Mantendo um baixo erro de regime estacionário, um sobressinal na ordem dos $20 \%$ e o tempo de resposta estipulado para 2 segundos. 


\section{CONCLUSÃO}

O presente trabalho deparou-se com o desfio de modelar o sistema de alimentação de combustível para motores common rail, dedicando-se ao objetivo de controlar a pressão do mesmo. Foi realizado o teste com um kit em bancada que simula parcialmente as condições reais de trabalho. Mas servindo como base para demonstrar a aplicabilidade do método e sua possível implementação futura num veiculo que adora um sistema idêntico, a saber a pick-up GM S-10.

As repostas obtidas mostram um desempenho satisfatório para o método de identificação aplicado ao sistema, a identificação por caixa preta, tornando-o uma ferramenta útil, para experimentações que não possibilitem suporte à modelagem de detalhada de todos os parâmetros físicos do sistema estudado.

Pose-se chegar a conclusão final que pelas vantagens práticas na identificação do sistema e implementação do controlador digital, como proposto. Estes procedimentos descritos habilitam a futura instalação de uma central eletrônica para gerenciamento de motor diesel common rail, com o controle de uma das mais importantes variáveis de operação do sistema.

\section{REFERÊNCIAS}

[1] ZHAO, Hua (org). Advanced direct injection combustion engine Technologies and development. Boca Raton-Cambridge: CRC-Woodhead, 2010.

[2] HEYWOOD, J. B. Internal combustion engine fundamentals. New York: McGrawHill, xxxiv, 930p, 1988.

[3] MARTINS, Jorge. Motores de Combustão interna. $2^{\mathrm{a}}$ ed. Editora Publindústria, 2006.

[4] MOLLENHAUER, Klaus; TSCHOEKE, Helmut (eds.). Handbook of Diesel Engines.

Berlin-Heidelberg: Springer-Verlag, 2010.

[5] REIF, Konrad. Diesel Engine Management: Systens and Components. Springer Fachmedien Wiesbaden, 2014.

[6] WANG, H.P; ZHENG, D.; TIAN, Y. High pressure common rail injection system modeling and control. ISA Transactions. Elsevier, Volume 63, Pag. 265-273, jul. 2016.

[7] GHAUTHIER, Christophe; SENAME, Olivier; DUGARD, Luc; MEISSONNIER, Guillaume. MODELLING OF A DIESEL ENGINE COMMON RAIL INJECTION

SYSTEM. IFAC, 16th Triennial World Congress, Prague, Czech Republic, 2005.

[8] GARCIA. C, PTC5719, Identificação de sistemas, LAC - EPUSP, 2016.

[9] ANGÉliCO. B, Notas de Aula PTC5611, Controle Digital de Sistemas Dinâmicos, LAC - EPUSP, 2016. 